\title{
COMPOSTAGEM COM DIFERENTES FONTES DE ESTERCOS ENRIQUECIDAS COM YORIN PARA POTENCIALIZAÇÃO DA FERTILIDADE DO SOLO
}

Luis Eduardo Vieira Pinto ${ }^{1}$, Thadeu Henrique Novais Spósito ${ }^{2}$, Fernando Bernardo Martins ${ }^{1}$, Alline Mendes Alves ${ }^{1}$, Lorrayne Guimarães Bavaresco ${ }^{1}$, Rodrigo Bernardo Soldá ${ }^{3}$, Felipe Silva Loosli ${ }^{1}$, Patrícia Rafaella de Mello ${ }^{1}$, Wilton Felipe Teixeira ${ }^{1}$

\footnotetext{
${ }^{1}$ Universidade do Oeste Paulista - UNOESTE, Programa de Pós-Graduação em Agronomia - Presidente Prudente/SP.

${ }^{2}$ Universidade Júlio de Mesquita Filho - Campus de Ilha Solteira/SP -Programa de Pós-Graduação em Agronomia.

${ }^{3}$ Universidade do Oeste Paulista - UNOESTE, Programa de Residência Agronômica - Presidente Prudente/SP. E-mail: levp@unoeste.br
}

\section{RESUMO}

A compostagem é o processo biológico de decomposição e de reciclagem da matéria orgânica contida em restos de origem animal ou vegetal. Os produtos da compostagem são largamente utilizados em substratos e na adubação do solo para produção agrícola em geral, como adubo orgânico devolve ao solo os nutrientes de que necessita, aumentando sua capacidade de retenção de água, permitindo o controle de erosão e reduzindo o uso de fertilizantes sintéticos. 0 experimento foi conduzido na ETEC de Presidente Prudente. Utilizou-se um delineamento experimental de blocos casualizados, contendo 3 tratamentos (composto), com 7 repetições (canteiros). Os tratamentos utilizados foram: T1 (compostagem produzida com esterco bovino), T2 (compostagem produzida com esterco suíno em confinamento) e T3 (testemunha). A utilização de ambos os compostos promoveu melhorias na fertilidade do solo, porém o composto produzido a partir do esterco suíno resultou em aumentos mais significativos no teor de matéria orgânica e nutrientes disponibilizados.

Palavras-chave: Agronegócio. Agroecologia. Sustentabilidade. Agricultura Familiar. Fertilidade.

\section{COMPOSTING WITH DIFFERENT SOURCES OF DUNGS YORIN ENRICHED TO ENHANCE SOIL FERTILITY}

\begin{abstract}
Composting is the biological process of decomposition and recycling of organic matter contained in remains of animal or vegetable origin. Composting products are widely used in substrates and in soil fertilization for agricultural production in general, as organic fertilizer returns to the soil the nutrients it needs, increasing its water retention capacity, allowing erosion control and reducing the use of Synthetic fertilizers. The experiment was conducted at the ETEC of Presidente Prudente. A randomized complete block design was used, containing 3 treatments (compound), with 7 replicates (beds). The treatments used were: T1 (compost produced with bovine manure), T2 (compost produced with swine manure in confinement) and T3 (control). The use of both compounds promoted improvements in soil fertility, but the compound produced from pig manure resulted in more significant increases in the content of organic matter and nutrients available.
\end{abstract}

Keywords: Agribusiness. Agroecology. Sustainability. Family Farming. Fertility. 


\section{INTRODUÇÃO}

A compostagem é um processo que pode ser utilizado para transformar diferentes tipos de resíduos orgânicos em adubo que, quando adicionado ao solo, melhora as suas características físicas, físico-químicas e biológicas. Proporciona mais vida ao solo, que apresenta produção por tempo mais prolongado e com maior qualidade. A técnica da compostagem foi desenvolvida com a finalidade de acelerar com qualidade a estabilização (também conhecida como humificação) da matéria orgânica. Na natureza, a humificação ocorre sem prazo definido, dependendo das condições ambientais e da qualidade dos resíduos orgânicos (COELHO, 2008).

O termo compostagem está associado ao processo de tratamento dos resíduos orgânicos sejam eles de origem urbana, industrial, agrícola e florestal. A compostagem é o processo de decomposição e estabilização biológica dos substratos orgânicos sob condições que favorecem o desenvolvimento de temperaturas termofílicas que resultam da produção biológica de calor. A compostagem é um processo de oxidação biológica através do qual os microrganismos decompõem os compostos constituintes dos materiais liberando dióxido de carbono e vapor de água (OLIVEIRA et al., 2008).

A técnica da compostagem é desenvolvida com a finalidade de acelerar com qualidade a estabilização da matéria orgânica. Como resultados da compostagem, são gerados dois importantes componentes para o solo: sais minerais, como nutrientes para as raízes das plantas e húmus, como condicionador e melhorador das propriedades físicas, físico-químicas e biológicas do solo. O composto possui nutrientes minerais, tais como nitrogênio, fósforo, potássio, cálcio, magnésio e enxofre. Todos esses minerais são assimilados em maior quantidade pelas raízes, além de ferro, zinco, cobre, manganês, boro e outros que são absorvidos em quantidades menores e, por isso, são denominados de micronutrientes (SARTORI et al., 2011).

O composto orgânico é o material obtido da compostagem, possui cor escura, é rico em húmus e contém de $50 \%$ a $70 \%$ de matéria orgânica. É classificado como adubo orgânico, pois é preparado a partir de estercos de animais e/ou restos de vegetais que, em estado natural, não têm valor agrícola. Recebe esse nome pela forma como é preparado, montando-se pilhas compostas de diferentes camadas de materiais orgânicos. A composição do composto orgânico, depende da natureza da matéria prima utilizada. Entende-se, desde já, que o benefício da matéria orgânica no solo não é apenas o de fornecedor de nutrientes para as plantas, mas, principalmente, de modificador, para melhorar suas propriedades físicas e biológicas (LIMA et al., 2004).

A compostagem de resíduos orgânicos é, provavelmente, o mais remoto sistema de tratamento biológico de que se serviu a humanidade, tendo sido utilizado pelas antigas civilizações como um método natural de reciclagem dos nutrientes, comumente presentes nos detritos resultantes de suas atividades diárias (DAI PRÁ et al., 2005).

Segundo Cortez (2009), os estercos são dejetos sólidos ou líquidos de animais domésticos cuja composição química depende do tipo de animal que o originou e do manejo do resíduo.

De acordo com Amorim et al. (2005), uma estratégia para o desenvolvimento da suinocultura com menor impacto ambiental ocasionado pela disposição inadequada dos dejetos no ambiente, é a adoção da reciclagem desses resíduos, de forma a permitir geração de energia renovável e/ou a estabilização da matéria orgânica, por meio da fermentação, antes do seu uso como adubo. Como alternativa ao sistema convencional de gestão dos dejetos de suínos, a compostagem tem apresentado resultados promissores.

O Brasil por possuir um dos maiores rebanhos bovinos do mundo, gera grandes quantidades de resíduos orgânicos, sendo o esterco bovino a fonte mais utilizada (FILGUEIRA, 2008). Isso porque ele possui potencial como agente beneficiador do solo, capaz de melhorar substancialmente muitas de suas características físicas e químicas, através da redução da densidade aparente, melhorando a permeabilidade, infiltração e retenção de água e a variação de temperatura dos solos, proporcionando acúmulo de nitrogênio orgânico, auxiliando no aumento 
do seu potencial de mineralização e disponibilidade de nutriente para as plantas, reduzindo o uso de fertilizantes (TEJADA et al., 2008).

O uso do esterco de animais, é, portanto, uma excelente alternativa para minimizar o impacto de resíduos obtendo insumos orgânicos com ótima qualidade, reduzindo a utilização de fertilizantes químicos (GOMES et al., 2008). É um sistema tecnológico de baixo custo, para a transformação de resíduos orgânicos em compostos que podem ter alto valor nutricional para as plantas (LOUREIRO et al.,2007).

Segundo Kiehl (1985) e Lopes (1989), o esterco suíno apresenta em sua base seca $53 \%$ de matéria orgânica, $1,9 \%$ de nitrogênio, $0,7 \%$ de $\mathrm{P}_{2} \mathrm{O}_{5}$ e $0,4 \% \mathrm{~K}_{2} \mathrm{O}$. Já o esterco bovino apresenta em sua base seca $57 \%$ de matéria orgânica, $1,7 \%$ de nitrogênio, 0,9\% de $\mathrm{P}_{2} \mathrm{O}_{5}$ e 1,4\% $\mathrm{K}_{2} \mathrm{O}$.

\section{METODOLOGIA}

O experimento foi conduzido na área experimental da ETEC - Escola Técnica Professor Dr. Antonio Eufrásio de Toledo (Colégio Agrícola) de Presidente Prudente/SP durante o período de agosto a dezembro de 2016. O clima da região se classifica em Aw, com estação chuvosa no verão e estação seca no inverno. Utilizou-se um delineamento experimental de blocos casualizados, contendo 3 tratamentos (tipo de composto), com 7 repetições (canteiros). Os tratamentos utilizados foram: T1 (compostagem produzida a partir de esterco bovino a pasto), T2 (compostagem produzida a partir de esterco suíno em confinamento) e T3 (testemunha - sem uso de composto).

A produção dos compostos foi realizada na própria ETEC a partir das matérias primas existentes na escola, foram confeccionadas duas leiras, uma para cada fonte de esterco, no qual possuíam 1 metro de diâmetro por 0,8 metros de altura. A composição da leira 1 era constituída por $18,2 \mathrm{~kg}$ de grama batatais; $101,1 \mathrm{~kg}$ de esterco bovino; 0,240 kg de Yoorin ${ }^{\circledR}$ Master, totalizando $119,54 \mathrm{~kg}$ de matéria prima com uma relação $\mathrm{C} / \mathrm{N}$ (carbono/nitrogênio) de 20/1. Já a leira 2 era constituída por $18,3 \mathrm{~kg}$ de grama batatais; 75,9 kg de esterco suíno; $0,240 \mathrm{~kg}$ de Yoorin ${ }^{\circledR}$ Master, totalizando $94,44 \mathrm{~kg}$ de matéria prima com uma relação $\mathrm{C} / \mathrm{N}$ de $15 / 1$. O Yoorin ${ }^{\circledR}$ Master foi adicionado a compostagem com o objetivo de potencializar o fornecimento de elementos como o fósforo, magnésio, silício, cálcio, enxofre, zinco, manganês, boro e cobre.

A confecção das leiras de compostagem foi realizada adicionando $30 \mathrm{~cm}$ de altura de grama batatais num espaço de $1 \mathrm{~m}^{2}$, em seguida foi adicionado uma camada de $10 \mathrm{~cm}$ de esterco e 80 gramas de Yoorin ${ }^{\circledR}$ Master, as camadas foram umedecidas e o procedimento foi repetido até a obtenção de três camadas de compostagem. Ao término da montagem das leiras, as mesmas foram protegidas com cobertura morta com o objetivo de manter a umidade presente no meio. Durante o período de 45 dias, as leiras eram molhadas de dois em dois dias, dos 45 aos 60 dias, término do processo de compostagem, as leiras eram molhadas apenas uma vez por semana. 0 revolvimento das leiras para oxigenação era realizado semanalmente durante o período de 60 dias.

Os blocos (canteiros) para a avaliação do efeito do composto, eram constituídos por pequenos canteiros contendo 1,1 metros de largura $x 1$ metro de comprimento e 0,2 metros de altura, totalizando 21 canteiros. Os canteiros onde foram adicionados os compostos receberam a quantia de $11 \mathrm{~kg}$ de material, seguindo as recomendações de aplicação de compostagem de Oliveira (2008). O composto foi incorporado ao solo a uma profundidade de 0,15 metros, após a incorporação o solo foi nivelado, protegido por cobertura morta e irrigado afim de umedecer os mesmos.

Passados 20 dias da incorporação do composto nos canteiros, foram retiradas 7 amostras de solo de cada tratamento, 21 amostras ao todo, e foram levadas para posterior análise química em laboratório especializado. Através das médias obtidas nos resultados das análises químicas do solo, gerou-se a tabela abaixo. 
Tabela 01. Média dos resultados da análise química do solo.

\begin{tabular}{|c|c|c|c|c|c|c|c|c|c|c|}
\hline \multirow{2}{*}{ Tratamentos } & $\mathrm{pH}$ & M.O. & $\mathrm{P}$ & $\mathrm{H}+\mathrm{Al}$ & K & $\mathrm{Ca}$ & $\mathrm{Mg}$ & \multirow{2}{*}{ SB } & \multirow{2}{*}{ CTC } & \multirow{2}{*}{ V\% } \\
\hline & $\mathrm{CaCl}_{2}$ & $\mathrm{~g} \mathrm{dm}^{-3}$ & $\mathrm{mg} \mathrm{dm} \mathrm{m}^{-3}$ & ............. & \multicolumn{3}{|c|}{$\mathrm{mmolc} \mathrm{dm}^{-3}$} & & & \\
\hline T1 & 6,3 & 20 & 203 & 13 & 4,0 & 65 & 19 & 88 & 101 & 87 \\
\hline $\mathrm{T} 2$ & 6,9 & 28 & 373 & 11 & 6,7 & 170 & 51 & 228 & 239 & 95 \\
\hline T3 & 6,0 & 13 & 205 & 14 & 2,4 & 43 & 9 & 55 & 69 & 80 \\
\hline
\end{tabular}

Todos os dados foram submetidos à análise de variância (ANOVA, $p<0,05$ ) e ao teste de comparação de médias Tukey $(p<0,05)$, segundo Silva (2011).

\section{RESULTADOS}

A partir dos resultados obtidos na tabela 02, observa-se que a utilização do composto orgânico independente da sua fonte, promoveu um aumento no teor de macronutrientes, bem como no teor de matéria orgânica, quando comparado com o tratamento onde não houve a incorporação do material orgânico junto ao solo.

Tabela 02. Resultados de análises estatísticas das variáveis analisadas "Matéria Orgânica (M.O.), Fósforo (P), Potássio (K), Cálcio (Ca) e Magnésio (Mg)" em relação aos diferentes tratamentos utilizados no experimento.

\begin{tabular}{cccccc}
\hline Tratamentos & M.O. & P & K & Ca & Mg \\
\hline T1 & $20 \mathrm{~b}$ & $203 \mathrm{~b}$ & $4,0 \mathrm{~b}$ & $65 \mathrm{~b}$ & $19 \mathrm{~b}$ \\
T2 & $28 \mathrm{a}$ & $373 \mathrm{a}$ & $6,7 \mathrm{a}$ & $170 \mathrm{a}$ & $51 \mathrm{a}$ \\
T3 & $13 \mathrm{c}$ & $205 \mathrm{~b}$ & $2,4 \mathrm{c}$ & $43 \mathrm{c}$ & $9,0 \mathrm{c}$ \\
\hline CV (\%) & 10,62 & 1,96 & 4,95 & 2,33 & 8,2 \\
\hline
\end{tabular}

Médias seguidas por letras iguais na coluna não diferem entre si pelo teste de Tukey a 5\%.

\section{DISCUSSÃO}

Observa-se que houve efeito da aplicação do composto produzido tanto do esterco bovino quanto do esterco suíno em todos os atributos de fertilidade do solo analisados. Os resultados condizem com Silva et al., (2001) que afirmam que o uso agrícola de resíduos para compostagem tem sido recomendado em virtude de proporcionar benefícios agronômicos, tal como a elevação do pH do solo. Vieira e Cardoso (2003) admite que o uso do composto orgânico proporciona um aumento na disponibilidade de macronutrientes no solo.

Por se tratar de um solo onde já existe a prática de olericultura, os valores de matéria orgânica e de alguns elementos como o fósforo, cálcio e magnésio já se encontravam com teores considerados altos, quando se baseando na tabela de limites de interpretação de nutrientes de Raij et. al., (1996).

Segundo Guerra et al. (2008) a matéria orgânica do solo apresenta-se como um sistema complexo de substâncias, cuja dinâmica é governada pela adição de resíduos orgânicos de diversas naturezas e por uma transformação contínua sob ação de fatores biológicos, químicos e físicos. A matéria orgânica do solo (MOS) desempenha um importante papel nas características químicas, físicas e microbiológicas do solo, sendo responsável por mais de $70 \%$ da capacidade de troca catiônica (CTC) dos solos tropicais. Nota-se que após o uso da compostagem os teores de macronutrientes e matéria orgânica foram significativamente elevados, refletindo diretamente na CTC e V\% do solo, resultando no seu enriquecimento químico e também biológico.

Quando comparado o composto produzido a partir de esterco suíno e de bovino, é possível perceber que para todas as variáveis analisadas há maior destaque para aqueles resultados oriundos do tratamento com o composto utilizado a partir do esterco suíno, isso pode ser justificado pelo fato de que o trato alimentar dos suínos em confinamento é melhor do que o trato alimentar dos bovinos a pasto, ou seja, devido aos nutrientes presentes na ração dos animais. 0 
que pode ser visto no trabalho de Figueroa (2008), quando o autor afirma que o esterco de galinha poedeira destaca-se dos outros em conteúdo de nutrientes, em especial, o nitrogênio, pois provém de aves alimentadas com rações concentradas. Com isso, as quantidades de minerais, sobretudo cálcio e fósforo, são superiores às fornecidas para frangos de corte, resultando num esterco mais concentrado que o da cama aviária (FUKAYAMA, 2008).

\section{CONCLUSÃO}

O uso da técnica de compostagem incorporada ao solo promove a potencialização da sua fertilidade.

O composto produzido a partir do esterco suíno favorece um maior incremento de matéria orgânica e nutrientes quando comparado com o composto de esterco bovino.

\section{REFERENCIAS}

AMORIM, A. C.; LUCAS JÚNIOR, J.; RESENDE, K. T. Compostagem e vermicompostagem de dejetos de caprinos: Efeito das estações do ano. Engenharia Agrícola, v.25, n.1, p.57-66. 2005.

https://doi.org/10.1590/S0100-69162005000100007

COELHO, F. C. Composto orgânico. Niterói - RJ. Julho de 2008. p. 04.

CORTEZ, J. W. M. Esterco de bovino e nitrogênio na cultura de rabanete. 2009. Disponível em http://www.fcav.unesp.br/download/pgtrabs/pv/m/3777.pdf. Acesso em: 02 maio. 2011.

DAI PRÁ, M. A. et al. Compostagem de dejetos líquidos de suínos. Sete Lagoas: Embrapa Milho e Sorgo, 2005. 25p. (Embrapa Milho e Sorgo. Documentos, 45).

FIGUEROA, E. A.; ESCOSTEGUY, P.; e WIETHÖLTER, S. Dose de esterco de ave poedeira e suprimento de nitrogênio à cultura do trigo. Revista Brasileira de Engenharia Agrícola e Ambiental. 2012. https://doi.org/10.1590/S1415-43662012000700003

FUKAYAMA, E. H. Características quantitativas e qualitativas da cama de frango sob diferentes reutilizações: efeitos na produção de biogás e biofertilizante. Tese de Doutorado. Faculdade de Ciências Agrárias e Veterinárias do Campus de Jaboticabal, Jaboticabal. 99p. (2008).

GOMES, J. J. A. et al., Composição química de composto orgânico preparado com esterco de eqüino e leucena. (Leucaena leucocephala Lam de Wit). Revista Brasileira de Agroecologia, Maranhão, v. 3, p.71-77, fev. 2008.

GUERRA, J. G. M.; SANTOS, G. A.; SILVA, L. S.; CAMARGO, F. A. O.; Macromoléculas e substancias humicas. In: Santos et al. Fundamentos da Matéria orgânica do solo - Ecossistemas tropicais e subtropicais. Porto Alegre. Metrópole. 2008.

KIEHL, E. J. Fertilizantes orgânicos. Piracicaba, Editora Agronômica Ceres Ltda, 1985. 492p.

LIMA, H. J. M.; OLIVEIRA, F. N. S.; CAJAZEIRA, J. P. Documentos 89 - Uso da Compostagem em Sistemas Agrícolas Orgânicos. Fortaleza, CE. Embrapa, Dezembro/2004. p. 09-16.

LOUREIRO, D.C. et al., Compostagem e vermicompostagem de resíduos domiciliares com esterco bovino para a produção de insumo orgânico. Pesquisa Agropecuára Brasileira, Brasília, v. 42, p.1043-1048, jul. 2007. https://doi.org/10.1590/S0100-204X2007000700018 
LOPES, A. S.; GUIMARÃES, P. T. G. Recomendações para o uso de corretivos e fertilizantes em Minas Gerais; 4⿳a aproximação. Lavras, CFSEMG. Comissão de Fertilidade do Solo do Estado de Minas Gerais, 1989. 176p.

OLIVEIRA, E. C. A.; SARTORI, R. H.; GARCEZ, T. B. Compostagem. Piracicaba, SP. Universidade de São Paulo, 2008. p. 2-16.

SARTORI, V. C.; RIBEIRO, R. T. S.; PAULETTI, G. F.; PANSERA, M. R.; RUPP, L. C. D.; VENTURIN, L. Compostagem - Produção de fertilizantes a partir de resíduos orgânicos. Caxias do Sul, RS. Universidade de Caxias do Sul, 2011. p. 2-15.

SILVA, F. C.; BOARETTO, A. E.; BERTON, R. S.; ZOTELLIH, B.; PEXE, C. A.; BERNARDES, E. M. Efeito na fertilidade de um Argissolo Vermelho-Amarelo cultivado com cana de açúcar. Pesquisa

Agropecuária Brasileira, v.36, p.831-840. 2001. https://doi.org/10.1590/S0100$\underline{204 \times 2001000500014}$

TEJADA, M.; GONZALEZ, J. L.; GARCÍA-MARTÍNEZ, A. M.; PARRADO, J. Effects of different green manures on soil biological properties and maize yield. Bioresource Technology, v.99, p.1758-1767, 2008. https://doi.org/10.1016/i.biortech.2007.03.052

VIEIRA, R. F.; CARDOSO, A. A. Variações nos teores de nitrogênio mineral em solo suplementado com lodo de esgoto. Pesquisa Agropecuária Brasileira, v.38, p.867- 874, 2003.

https://doi.org/10.1590/S0100-204X2003000700011 